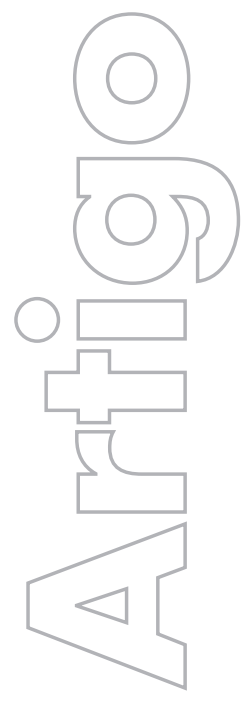

revista

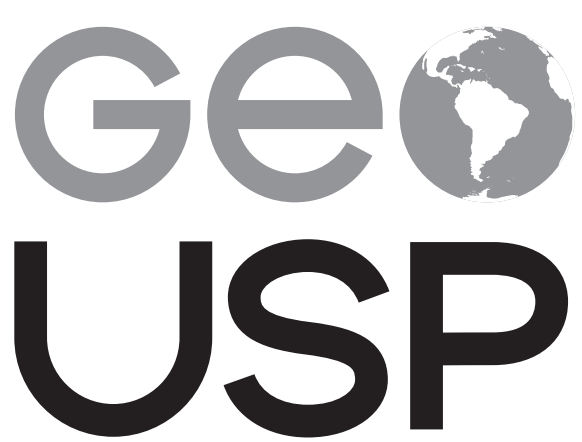

espaço e tempo

Volume $20 \cdot n^{\circ} 2(2016)$

\section{Geografia e arqueologia:} análise espacial e contextual de sítios arqueológicos no estuário amazônico

Cristina do Socorro Fernandes Senna UFPA/MCTI

p. $238-249$

Como citar este artigo:

SENNA, C. S. F. Geografia e arqueologia: análise espacial e contextual de sítios arqueológicos no estuário amazônico. Geousp - Espaço e Tempo (Online), v. 20, n. 2, p. 238-249, mês. 2016. ISSN 2179-0892.

Disponível em: <http://www.revistas.usp.br/geousp/issue/ view/6465> . doi: http://dx.doi.org/10.11606/issn.2179-0892. geousp.2014.84539.

\section{(c) $(1) \Theta$}

Este artigo está licenciado sob a Creative Commons Attribution 4.0 License. 


\title{
Geografia e arqueologia: análise espacial e contextual de sítios arqueológicos no estuário amazônico
}

\begin{abstract}
Resumo
As contribuições teórico-metodológicas da ecologia de paisagem com enfoque geográfico foram aplicadas à análise espacial e contextual de três sítios arqueológicos (PA-BA-83: Bittencourt, PA-BA-84: Alunorte e PA-BA-85: Jambuaçu) do projeto Arqueológico Bauxita Paragominas, no estuário amazônico. Os resultados mostraram que os artefatos, biofatos e ecofatos resgatados remetem à tradição ceramista Tupi-Guarani, que, no último milênio, desenvolveu atividades de horticultura em floresta tropical, sendo o plantio de mandioca, a caça e a coleta de frutos silvestres a principal economia do grupo, embora também mantivessem forte ligação com a planície flúvio-marinha, sobretudo para obter recursos alimentares como frutos de palmeiras, crustáceos e peixes.
\end{abstract}

Palavras-chave: Paisagem. Arqueologia. Patrimônio. Estuário. Amazônia.

\section{Geography and archeology: spatial and contextual analysis of archaeological sites in the Amazonian estuary}

\begin{abstract}
The archaeological research on Amazon Basin during the last fifty years utilized conventional approach to investigate archaeological sites for heritage conservation due the strong impact caused by mineral exploration projects. Therefore, new approaches utilizing Landscape Ecology approach shows the integration among different scientific disciplines as archaeology, geophysics, botany, soil science, and geography for integrated analysis of the human occupation of the Amazon estuary during the last millennium. The results show 3 archaeological sites related to Tupi-Guarani Cultural Tradition, dated ${ }^{14} \mathrm{C}$ method between $980 \pm 40 \mathrm{BP}$. and $110 \pm 40 \mathrm{BP}$.
\end{abstract}

Keywords: Landscape. Archaeology. Heritage. Estuary. Amazonia.

\section{Introdução}

Nos últimos 50 anos, a pesquisa arqueológica na Amazônia voltou-se para projetos de salvamento arqueológico, que buscavam mapear, investigar e resgatar a cultura material de sítios arqueológicos pré-históricos, em áreas de empreendimentos minero-metalúrgicos, hidre- 
létricas, construção de estradas e pontes, entre outros (Lopes, D.; Silveira; Magalhães, 1988; Costa, 1993; Pereira, E. S., 1999). Esses empreendimentos causaram forte impacto ao patrimônio cultural da área focal, com a destruição de importantes vestígios da cultura material de grupos culturais, representantes da rica e diversa tradição ceramista de horticultores de floresta no âmbito do bioma Amazônia (Simões, 1983; Roosevelt, 2006; Neves, 1999).

A Amazônia sempre foi detentora de um rico acervo arqueológico, resgatado e estudado por pesquisadores desde o século XIX, tais como Domingos Soares Ferreira Penna, João Barbosa Rodrigues, Aureliano Lima Guedes, Ladislau Netto, Charles Hartt e Orville Derby. As informações e as coleções organizadas por esses pioneiros, ainda são referências importantes para as investigações arqueológicas na atualidade (Barreto, 1999/2000; Neves, 1999).

O acervo arqueológico brasileiro inclui a cerâmica, artefatos líticos, restos de fogueiras, enterramentos. Ele é protegido pelo Decreto-lei n. 25, de 30 de novembro de 1937, que organiza e incentiva a proteção do patrimônio histórico e artístico nacional, e pela Lei n. 3.924, de 26 de julho de 1961, que dispõem sobre monumentos arqueológicos e pré-históricos de qualquer natureza existentes no território nacional.

A pesquisa arqueológica no estuário amazônico foi desenvolvida a partir do Programa de Arqueologia Preventiva na Área de Influência do Projeto Bauxita Paragominas/PA (Lopes, P. et al., 2008), segundo a norma instituída pela Portaria n. 230, do Instituto do Patrimônio Histórico e Artístico Nacional (Iphan), abrangendo três fases: a prospecção, a escavação e a análise dos vestígios arqueológicos em laboratório, levando em conta as complexas interações espaciais, ambientais e socioeconômicas dos sítios PA-BA-83: Bittencourt, PA-BA-84: Alunorte e PA-BA-85: Jambuaçu, no contexto do estuário amazônico.

Assim, os sítios Bittencourt, Jambuaçu e Alunorte não apenas integram o meio físico do estuário, porém, também constituem a paisagem local, utilizada e manejada pelas populações humanas na pré-história, constituindo o espaço vivido. As pesquisas arqueológicas realizadas nos municípios de Moju, Abaetetuba e Barcarena, entre os anos de 1980 e 2000, descobriram 23 sítios arqueológicos, classificados em pré-colonial e colonial, estes sítios hoje praticamente destruídos. Outras populações ocuparam essas mesmas áreas, posteriormente, desde o período colonial até hoje, transformando ainda mais a paisagem estuarina.

O presente artigo é uma contribuição da ecologia de paisagem, integrando as investigações arqueológicas ao enfoque geográfico, objetivando compreender as formas de convívio das populações pré-históricas com a floresta tropical úmida, no contexto geoambiental e/ou geoecológico do estuário amazônico, a partir da análise da paisagem, do espaço habitado e do entorno explorado, juntamente com a cultura material do grupo social, a partir da contribuição de dados de outras disciplinas científicas como a geofísica, botânica, pedologia e geomorfologia.

\section{Área de estudo}

O projeto Albrás/Alunorte é um empreendimento que dista $40 \mathrm{~km}$ em linha reta de Belém, capital do estado do Pará, localizado no estuário amazônico, que tem 300 km de extensão, começa na baía de Bocas, no município de Breves, prosseguindo pelo rio Pará, que recebe toda a massa de águas do Tocantins. Inclui também a baía do Guajará, que recebe a embocadura dos rios Guamá, Moju, Acará e Capim, em frente à cidade de Belém, passando à alongada baía de Marajó (Ab’Saber, 2006). 
Os sítios arqueológicos PA-BA-83: Bittencourt, PA-BA-84: Alunorte e PA-BA-85: Jambuaçu ficam em municípios diferentes, que integram o setor continental estuarino da zona costeira do estado do Pará (Alves, M. et al., 2005), em termos fisiográficos, tendo o rio Pará como principal drenagem, onde desembocam os rios locais (Figura 1).

Figura 1 - Mapa de localização dos sítios arqueológicos no estuário amazônico

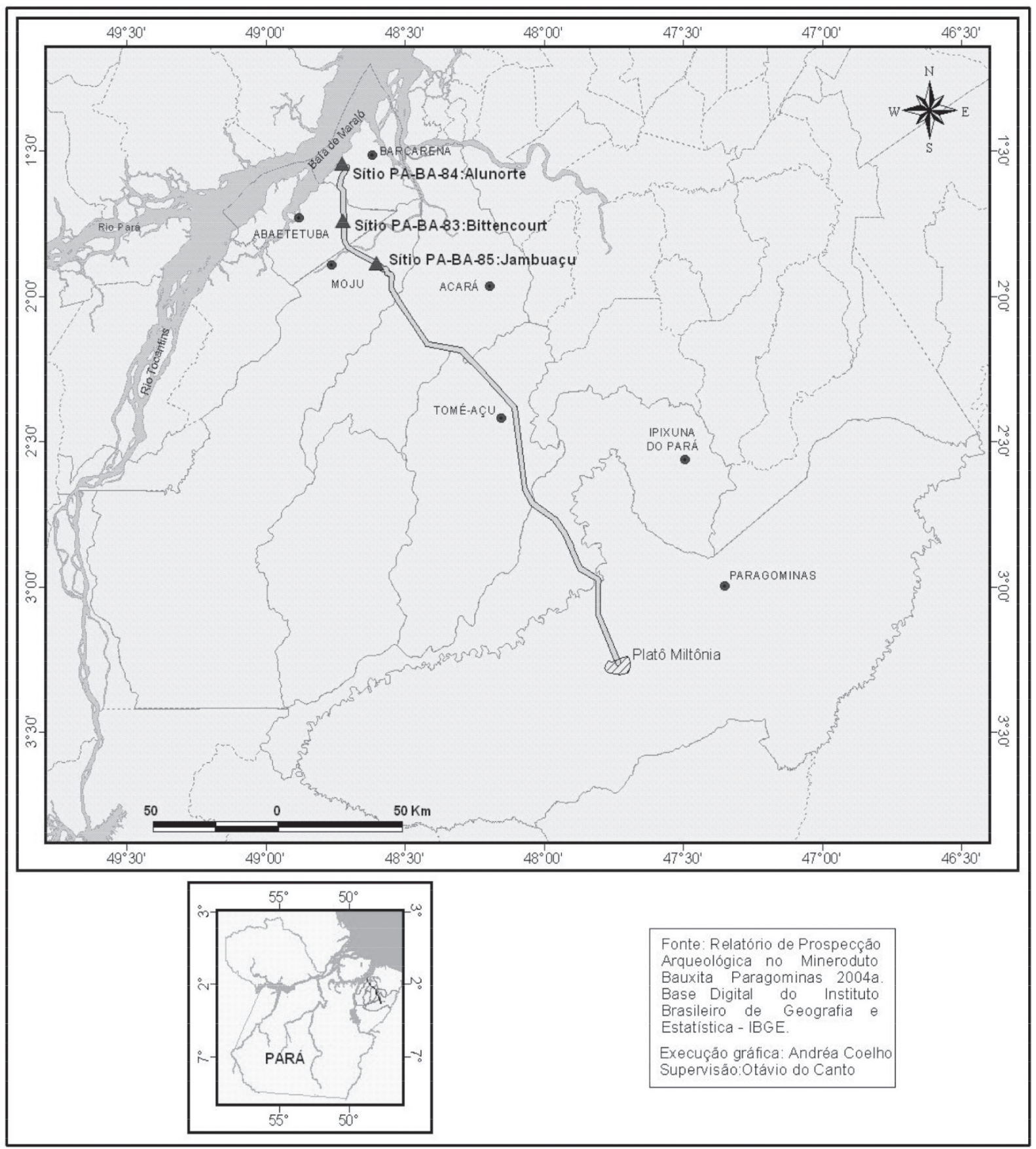

A história geológica da área de estudo é representada pelo Neógeno Superior, com a formação barreiras, com depósitos de conglomerados, arenitos e argilitos siliciclásticos, continentais do Plioceno (Rossetti; Góes, 2004), integrando o Planalto Rebaixado da Amazônia, cujo relevo é tabular por efeito erosivo, enquanto os depósitos aluviais recentes, constituídos por cascalhos, areias e argilas inconsolidadas, retrabalhados da unidade precedente datam 
do Holoceno. Localmente, ocorrem depósitos argilo-orgânicos constituindo a planície flúvio-marinha (Lima; Tourinho; Costa, 2000), cujos dados palinológicos remetem à ocorrência de antigos bosques de mangue, datados do último milênio (Senna et al., 2007).

As formações geológicas atreladas às feições morfológicas que se destacam na paisagem estuarina favorecem o predomínio das classes latossolos amarelos distrófico de textura variada, latossolos coricrecionários, argissolos amarelos, neossolos quartzarênicos e neossolos flúvicos (Oliveira, 2002, p. 26).

Os levantamentos florísticos realizados na área de estudo destacam duas formações vegetais: (1) vegetação secundária ou capoeira, compreendendo 70\% da cobertura vegetal, com árvores de idade estimada entre 25 e 35 anos e altura média de $11,72 \mathrm{~m}$ e (2) floresta de várzea ou floresta de baixio, com árvores atingindo altura média de $13,51 \mathrm{~m}$ e alguns pontos de transição entre capoeira e a várzea. Entretanto, há o registro de pequenos enclaves de bosques de mangue, com indivíduos de Rhizophora mangle L. e Avicennia germinans L. Stearn, misturados à vegetação de várzea, sempre margeando os rios.

Espécies de plantas semidomesticadas e/ou domesticadas foram registradas em meio a capoeiras como Theobroma grandiflorum Schaum (cupuaçu), Euterpe oleracea Mart. (açaí) Caryocar villosum Aubl. (piquiá), Mangifera indica L. (manga), e Rheedia macrophylla Planch. et Triana. (bacuri-pari), os indivíduos com altura variando de 9-11 m, sobreviventes locais de antigas ocupações coloniais conhecidas localmente como taperas.

O sítio arqueológico PA-BA-83: Bittencourt fica na margem esquerda do rio Arapiranga de Beja, município de Abaetetuba, com a população da comunidade Colônia Nova habitando a área do referido sítio e seu entorno. A principal ocupação da comunidade é a agricultura tradicional de roçados, consorciados com várias outras espécies vegetais como, por exemplo, o milho (Zea mays L.) e o arroz (Oryza sativa L.). Entretanto, para estes pequenos produtores, a principal cultura é a mandioca (Manihot esculenta, Crantz). Na área do entorno das habitações são cultivados espécies frutíferas, terapêuticas e ornamentais, sendo também frequente a presença de hortas e a criação de pequenos animais.

O sítio arqueológico PA-BA-84: Alunorte fica na margem esquerda do igarapé Murucupi, município de Barcarena, onde estão a unidade de produção e a área de rejeitos sólidos da Alunorte, constituindo o complexo industrial Albrás-Alunorte, juntamente com as vilas de Itupanema e dos Cabanos em seu entorno. Tem-se acesso ao sítio Alunorte por via rodoviária, saindo de Belém pela alça viária e tomando a PA-481, num percurso de $110 \mathrm{~km}$. Há também transporte fluvial, saindo do porto da empresa Trans-Arapari, às margens do rio Guamá, no bairro de mesmo nome em Belém, adentrando o rio Pará e desembarcando em suas margens, na vila de Arapari, município de Barcarena, perfazendo 8 km na direção sul.

○ sítio arqueológico PA-BA-85: Jambuaçu está fica na margem direita do rio Jambuaçu, na comunidade de São Bernardino, município de Moju. A população sobrevive da agricultura, do extrativismo vegetal e animal, da pesca artesanal de subsistência e da criação de gado bovino em pequena escala, como também de pequenos animais. Tem-se acesso à comunidade por meio de estrada não pavimentada, distando cerca de $20 \mathrm{~km}$ da sede municipal e da PA-151. Antes de sua construção, o rio Jambuaçu era a principal via de transporte. Atualmente, esse curso d'água ainda é importante para o escoamento da produção local, além de constituir-se 
em fonte de alimentação pela prática da pesca de subsistência, mantendo, portanto, o modo de vida ribeirinho. Ao longo de suas margens, em direção ao rio Moju, há muitas madeireiras tradicional atividade do município.

\section{Procedimentos metodológicos: ecologia de paisagem aplicada a estudos arqueológicos}

O enfoque metodológico da ecologia de paisagem (Pereira, E. M., 2008) diferencia e caracteriza unidades de paisagem, uma vez que considera a paisagem um sistema espacialmente heterogêneo, cujos padrões espaciais e temporais refletem a dinâmica ambiental, em termos de seus elementos bióticos, abióticos e antrópicos constituintes.

Estabelecer relações entre padrões, processos e escalas remete à compreensão dos fatores que criam a heterogeneidade das paisagens e pode refletir os processos naturais e antrópicos, operando em diferentes escalas.

A ecologia de paisagem foi aplicada à pesquisa arqueológica no estuário amazônico com análise contextual e espacial, juntamente com dados oriundos de diferentes disciplinas científicas como geofísica, botânica, pedologia e geomorfologia, o que facilitou a interpretação dos processos de ocupação humana e a compreensão dos processos de deposição arqueológica e remobilização pós-deposicional de artefatos, ecofatos e biofatos no solo. Essa abordagem é mais frequente no exterior (Butzer, 1989; Renfrew; Bahn, 1993), enquanto no Brasil ainda há poucos trabalhos nessa linha (Roosevelt, 1991; Senna, 1991; Senna et al., 2007; Pereira, E. M., 2008).

A ecologia de paisagem aplicada aos estudos arqueológicos procura sítios arqueológicos em grandes áreas geográficas, a partir de prospecção geofísica, técnicas de levantamentos e mapeamento topográfico, delimitando áreas de ocupação, a partir de estruturas, feições e artefatos arqueológicos, que se encontram nas áreas internas e externas dos sítios arqueológicos.

Na prospecção geofísica, foram empregados o método magnético, radiométrico e o radar de penetração no solo (Georadar ou GPR) nos sítios. Esta metodologia é também aplicada como ferramenta de prospecção arqueológica fora do Brasil (Aitken, 1961). Na Amazônia, os primeiros experimentos iniciaram na década de 1980 (Alves, J.; Lourenço, 1981; Roosevelt, 1991), sendo cada vez mais utilizados.

As medidas com o Georadar são tomadas com o equipamento GSSI modelo SIR. 3000 e antena de $400 \mathrm{MHz}$. $\bigcirc$ registro do radar é efetivado no modo tempo, com o controle da distância sendo feito com auxilio de trena e a inserção de marcas no registro, a cada 5 metros.

Os trabalhos de prospecção geofísica, juntamente com o mapeamento de sítios arqueológicos e sua escavação, mostram a importância da análise espacial no direcionamento dos trabalhos de campo, pois os fenômenos raramente aparecem distribuídos de forma homogênea no território. As características topográficas, os climas, as comunidades biológicas e os grupos humanos traduzem um modelo espacial e são, portanto, suscetíveis de análise no âmbito da geografia (Butzer, 1989, p.7).

Essa percepção, de natureza multidisciplinar, considera o contexto espacial próprio da análise geográfica, possibilitando a localização precisa dos sítios arqueológicos a partir da prospecção geofísica cujos resultados visam otimizar boas técnicas de intervenção no sítio arqueológico, levando em conta as estruturas remanescentes, os vestígios da terra preta arqueológica (TPA) relacionados com o entorno ambiental e as possíveis fontes de matéria-prima. 
Para os povos agricultores, é a qualidade da terra que leva à ocupação do território, pois está expressa na textura dos solos, no tipo de vegetação, no uso atual e histórico dos terrenos, na disponibilidade de água, assim como nos fatores limitativos, que são causados, por exemplo, pelo clima ou pela variação topográfica (Martínez; Zapatero, 1984, p. 62-63).

As coletas arqueológicas sistemáticas em superfície e sub-superfície foram realizadas por meio de prospecções amplas e escavação por níveis naturais, em unidades de $1 \mathrm{~m} \mathrm{X} 1 \mathrm{~m}$, com coletas sistemáticas desde a superfície, chegando a $30 \mathrm{~cm}$ de profundidade, em busca de artefatos, ecofatos e biofatos.

As amostras sedimentares e de carvão arqueológico foram datadas pelo método radiocarbônico ${ }^{14} \mathrm{C}$ no Laboratório de Datação Radiocarbônica Beta Analytic, no estado da Flórida, EUA.

Para a análise de ecofatos, os estudos pedológicos em Arqueologia (Lehmann et al., 2003) empregam no campo, a descrição morfológica dos perfis de solo, definem a coloração do solo (Munsel Colors Company, 1975), a descrição da textura, estrutura, consistência, tipos de transição entre os horizontes e quantidade de raízes, com posterior análise química em laboratório, a partir de amostras de solo TPA, obtidas dos três sítios, em trincheiras que chegaram à profundidade de $1,30 \mathrm{~m}$.

Os estudos palinológicos em grãos de pólen produzidos por angiospermas e gimnospermas, bem como esporos provenientes de pteridófitas, briófitas, algas e fungos, foram empregados na análise de biofatos, baseando-se também no conhecimento da flora local e regional, biologia da produção e dispersão de grãos de pólen, avaliando constantemente, os dados obtidos na reconstrução de ambientes passados, na detecção de atividades humanas e na delimitação de paisagens culturais (Pearsall, 2000).

A análise espacial considera o contexto de um artefato arqueológico proveniente de uma feição, um sítio, uma cultura, sendo o componente de associações que são relevantes para seu significado, integrando os lugares dos achados cerâmicos, líticos, relacionados às estruturas internas do sítio e associadas também aos territórios exteriores e às fontes de matéria-prima (Butzer, 1989; Martínez; Zapatero, 1984; Schiffer, 1972).

Assim, as análises das complexas relações socioculturais da área em estudo no período pré-colonial, mostram o contexto do antigo assentamento indígena na paisagem, considerando os entornos geográficos e ecológicos reorganizados e explorados pelos povos, o redimensionamento sociocultural implantado pela nova ordem firmada entre o indígena e o europeu, chegando à condição atual do jazimento.

\section{Resultados e discussão}

Os dados geofísicos mostraram a extensão da área geográfica dos sítios, considerando seu interior e os arredores, segundo a proposta de Martínez e Zapatero (1984), pela qual a área interna está relacionada à análise de artefatos e das estruturas evidentes no sítio, enquanto a área externa é seu entorno circundante, onde se inserem a fauna e a flora, as fontes de matéria-prima, os recursos naturais, a exploração econômica e a manipulação/explotação dos recursos pertencentes às diferentes paisagens.

Os sítios pesquisados trouxeram elementos da cultura material tanto pré-colonial, quanto histórica. Assim, fez-se a separação entre os processos do período pré-colonial com aqueles dos tempos históricos, entendendo que essa divisão é apenas conceitual. 
Portanto, outra abordagem, diferente da adotada, poderia acarretar prejuízos às interpretações, haja vista que o corte cronológico impede a visão do processo cultural como um todo (Lightfoot, 1995, p. 211).

mapeamento e a escavação arqueológica possibilitaram a descoberta das prováveis dimensões dos sítios, o grau de preservação, sua contextualização na paisagem, a contextualização dos artefatos, biofatos e ecofatos na escala do sítio e a identificação de possíveis áreas de atividades humanas intrassítios.

Os dados de campo levantados no mapeamento e escavações evidenciaram uma sequência temporal, ora interrompida pelas intervenções antrópicas ao longo do tempo, ora preservadas e passíveis de melhor interpretação, indicando que a forma dos sítios arqueológicos estava bastante alterada, assim como a morfologia do solo TPA e o contexto ambiental, principalmente no PA-BA-83: Bittencourt e no PA-BA-85: Jambuaçu (Tabela 1).

\section{Tabela 1 - Descrição da macromorfologia e micromorfologia de solos TPA dos sítios arqueológicos estudados}

\begin{tabular}{|c|c|c|}
\hline sítio arqueológico & macromorfologia & micromorfologia \\
\hline PA-BA-83: Bittencourt & $\begin{array}{l}\text { Típico solo TPA, com a coloração do } \\
\text { A antrópico, alcançando maior espes- } \\
\text { sura que os horizontes A das áreas } \\
\text { adjacentes, preto na carta de Munsell; } \\
\text { presença de fragmentos cerâmicos e } \\
\text { líticos. A alta abundância de carvão é } \\
\text { resultado da agricultura de subsistên- } \\
\text { cia das populações tradicionais. }\end{array}$ & $\begin{array}{l}\text { A mineralogia é formada por } \\
\text { quartzo e argila do tipo Caolini- } \\
\text { ta; os constituintes do solo são } \\
\text { mais agregados, os poros têm } \\
\text { dimensões variadas e formas } \\
\text { arredondadas, com a presença } \\
\text { de muitos fragmentos vegetais. }\end{array}$ \\
\hline PA-BA-84: Alunorte & $\begin{array}{l}\text { Solo TPA ainda não formado, com } \\
\text { predomínio de cores brunadas e acin- } \\
\text { zentado na coloração do horizonte } \\
\text { A antrópico; presença de cerâmica e } \\
\text { faiança. Presença de carvão abundan- } \\
\text { te, relativo à estrutura de uma foguei- } \\
\text { ra doméstica pré-colonial. }\end{array}$ & $\begin{array}{l}\text { A mineralogia é constituída por } \\
\text { quartzo e argila do tipo Cao- } \\
\text { linita; os constituintes do solo } \\
\text { são menos agregados, entre os } \\
\text { poros, predominam formas e } \\
\text { dimensões variadas, há muitos } \\
\text { fragmentos vegetais, carvões e } \\
\text { microalgas diatomáceas. }\end{array}$ \\
\hline PA-BA-85: Jambuaçu & $\begin{array}{l}\text { A coloração do A antrópico alcançou } \\
\text { preto bastante espesso em relação } \\
\text { ao horizonte A das áreas adjacentes; } \\
\text { presença de cerâmica, líticos e cons- } \\
\text { truções em pedra, menor ocorrência } \\
\text { de carvão do que os sítios anteriores. }\end{array}$ & $\begin{array}{l}\text { A mineralogia é constituída por } \\
\text { quartzo e argila do tipo Caolinita; } \\
\text { os constituintes do solo são mais } \\
\text { agregados; os poros têm formas } \\
\text { arredondadas e dimensões varia- } \\
\text { das, predominantemente. }\end{array}$ \\
\hline
\end{tabular}

fonte: Modificado de P. Lopes e outros (2008).

Hodder (1984) chama atenção para os cuidados na interpretação das áreas de atividades em um sítio, devido à possível reutilização de objetos para novas atividades e a informação parcial sobre os artefatos recuperados, ou parcialmente usados. Esses diferentes contextos 
podem ser percebidos a partir da análise espacial, incluindo informações a respeito da natureza dos artefatos, seu contexto deposicional, pós-deposicional e a natureza do agrupamento onde ocorreram.

Ao posicionar os artefatos, cuja contextualização no território remete à interpretação de diferentes áreas, podem-se delinear os processos de lixiviação do material arqueológico, causada pela água da chuva, pela erosão do solo, por raízes, pela queda de árvores, pela construção de residências ou por outros empreendimentos como o próprio mineroduto, por exemplo.

Mesmo destruído, o sítio arqueológico Bittencourt mostrou 2.938 fragmentos de cerâmica indígena e 28 fragmentos de cerâmica cabocla, concentradas numa pequena área do sítio (escavação $n^{\circ}$ 6) que foi definida como área de descarte, e em outra, designada escavação $n^{\circ} 7$, caracterizada como uma possível área de habitação. Os fragmentos dessa área são multicomponenciais e incluem vidro, metais, louças e botões, entre outros, e estavam muito fracionados e misturados ao longo dos perfis abertos pelas escavações (Lopes, P. et al., 2008).

$\bigcirc$ sítio arqueológico Alunorte estava mais bem conservado. As escavações foram feitas em 12 setores de diferentes dimensões, espalhados em uma área de aproximadamente $570 \mathrm{~m}$ X 300 m e apresentando 3.253 fragmentos de cerâmica indígena, 16 fragmentos de cerâmica cabocla e 156 fragmentos de cerâmica de torno, além de lascas líticas, miçangas, contas e faianças (Lopes, P. et al., 2008).

No sítio arqueológico Jambuaçu foi identificada uma mancha de solo escuro com a presença de 8.745 fragmentos de cerâmica indígena, 39 fragmentos de cerâmica cabocla e 1.521 fragmentos de cerâmica de torno, sendo essa área definida como habitação e descarte, constatando-se também a presença de alguns fragmentos de faianças, botões, contas e metais (Lopes, P. et al., 2008).

As análises arqueológicas em laboratório mostraram que os artefatos cerâmicos estão associados, em termos estilísticos, à cultura material da etnia Tupinambá (Tupi), dominante na época do contato com os europeus, bem como ao longo do período colonial, sendo encontrados ao longo de toda a costa paraense e em especial nos municípios de Moju, Abaetetuba e Barcarena, no estado do Pará (Lopes, P. et al., 2008).

Os dados de datações ${ }^{14} \mathrm{C}$ em carvões arqueológicos coletados durante as escavações fornecidos por P. Lopes e outros (2008) mostraram pouca variação, e a base do sítio PA-BA-83: Bittencourt foi datada em 970 40 A.P. (Beta - 217.581), enquanto o topo foi formado em 170 160 A.P. (Beta - 217.578). $\bigcirc$ sítio PA-BA-84: Alunorte apresenta a datação para a base de 980 \pm 40 A.P. (Beta - 217.584) e a de topo $110 \pm 40$ A.P. (Beta - 217.582). $\bigcirc$ sítio PA-BA-85: Jambuaçu mostrou a base datada em 740 440 A.P. (Beta - 217.586), o topo em $150 \pm 60$ A.P. (Beta - 217.585).

Os resultados das análises palinológicas nos sítios PA-BA-83: Bittencourt, PA-BA-84: Alunorte e PA-BA-85: Jambuaçu mostraram que as atividades antrópicas desde o contato com o europeu, superpostas às ocupações pré-históricas, mascararam qualquer evidência de uso de recursos naturais vegetais. A prática secular de agricultura familiar, com o uso do fogo certamente destruiu qualquer pista que pudesse ser fornecida pela análise de pólen.

Entretanto, as análises de pólen em um testemunho sedimentar da praia de Itupanema (IT1), município de Barcarena/Pará evidenciaram, a partir da análise de composição, abundância relativa e frequência de ocorrência de táxons polínicos em sedimentos, três ecozonas típicas 
de ambiente flúvio-estuarino, porém com variações no sistema deposicional, cuja base e o topo apresentam sedimentos arenosos e areno-orgânicos evidenciando maior energia, muito próximos ao sistema atual, típico de várzea, datados na base em $930 \pm 40$ anos A.P. (Beta 217.590), separados por sedimentos de coloração cinza, argilo-orgânicos e abundantes restos vegetais, datados em $520 \pm 40$ anos A.P. (Beta 217.591), depositados em ambiente de baixa energia, ligados à mistura de vegetação de várzea e manguezal (Senna et al., 2007).

As datações ${ }^{14} \mathrm{C}$ relativas à ocupação humana do estuário amazônico têm forte correlação com as datações obtidas em sedimentos de um provável paleomangue que existia nas proximidades do sítio Alunorte, que certamente servia de área de captação de recursos alimentares para as populações ceramistas pré-históricas, que exploravam os ambientes flúvio-estuarinos, com manguezais associados, e em cuja vida cotidiana e subsistência as palmeiras foram importantes, assim como os recursos faunísticos dos manguezais (Senna et al., 2007).

Assim, a ocupação humana da região desenvolveu-se ao longo dos últimos mil anos, sendo, portanto, de longa duração, iniciado no período pré-colonial e alcançando a atualidade, conforme já evidenciado pela cultura material de diferentes épocas, existente em todas as áreas estudadas.

\section{Figura 2 - Abundância relativa de grãos de pólen (B) ao longo do teste- munho IT1, coletado na praia de Itupanema, município de Barcarena-PA}

\% Abundância Itupanema - IT1
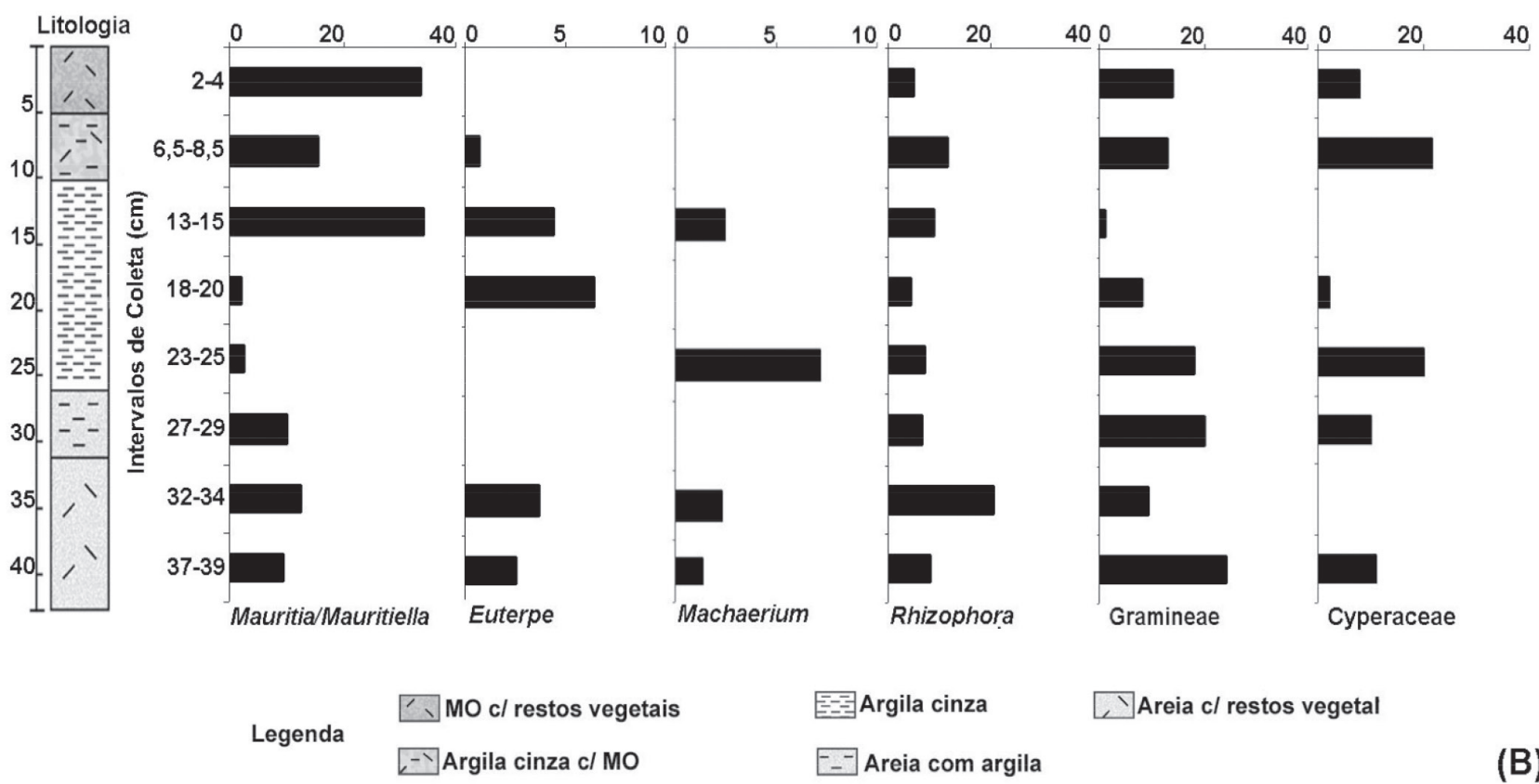

(B)

fonte: Modificado de Senna e outros (2007).

\section{Considerações finais}

Os resultados alcançados neste artigo respondem a seus objetivos, pois, integrando investigações arqueológicas ao enfoque geográfico, a ecologia de paisagem permitiu compreender as formas de convívio das populações pré-históricas com a floresta tropical úmida, no contexto geoambiental e/ou geoecológico do estuário amazônico no último milênio. 
Entretanto, no que tange à interação ou inter-relação dos objetos espaciais no limite de abrangência ou na aplicação da geografia física, há que considerar que as leituras estão mais afinadas com a ecologia. Essa relação da geografia física com a ecologia explica-se pela tentativa de superar estudos de caráter apenas fisiográfico, e a visão geográfica foi o viés da aplicação da ecologia da paisagem ao estudo de sítios arqueológicos.

Num contexto sistêmico e dinâmico, foi possível aplicar a ecologia de paisagem ao estudo de sítios arqueológicos com o uso de diferentes elementos da paisagem flúvio-marinha presentes nos artefatos, ecofatos e biofatos encontrados no macromeio e no micromeio dos sítios arqueológicos.

A interpretação dos dados levantados por cada disciplina destacou, em parte, aspectos importantes da relação homem-paisagem no macromeio e no micromeio dos sítios arqueológicos PA-BA-83: Bittencourt, PA-BA 84: Alunorte e PA-BA-85: Jambuaçu. Portanto, integrada à própria análise espacial dos sítios arqueológicos, a análise sistêmica da paisagem pressupôs a interação de duas escalas espaciais: o macromeio e micromeio dos sítios, no contexto da paisagem flúvio-marinha do estuário amazônico.

Os levantamentos botânicos permitiram identificar espécies vegetais atuais e sua relação, como comunidade, aos diferentes aspectos da paisagem continental e da flúvio-marinha, possibilitando comparar esses dados com os dados palinológicos em sedimentos e solos TPA, cujos resultados remetem a uma vegetação diferente, existente no passado, gerando boas correlações a partir das datações ${ }^{14} \mathrm{C}$ entre o processo de ocupação pré-colonial e a dinâmica da paisagem movida pelos processos mesológicos.

A prospecção geofísica permitiu definir zonas anômalas geradas na paisagem por intervenções humanas relativas aos materiais arqueológicos encontrados nas escavações, classificados em artefatos, biofatos e ecofatos. Todas as anomalias foram testadas por meio de escavações que ensejaram a interpretação dos tipos de anomalia existentes na área e a elaboração de um painel mais preciso destas.

As coletas de superfície e as intervenções em sub-superfície, a análise da paisagem e a observação do uso do território pelas populações humanas atuais se demonstraram adequadas, pois permitiram identificar onde havia possíveis habitações atuais e roçados antigos nas proximidades das escavações.

Abrindo picadas, notou-se que a área havia passado por muitas intervenções humanas: construção de estradas e ramais, construção de casas, plantações, criação de animais domésticos, construção de cercas e implantação de dois minerodutos - Pará Pigmentos S.A. e Imerys Capim Caulim. Esses processos destrutivos dificultaram uma visão mais detalhada e a definição do formato dos sítios arqueológicos.

Essas perturbações nos solos TPA também dificultaram a interpretação dos horizontes estratigráficos e a análise contextual e espacial dos fragmentos de artefatos arqueológicos neles dispostos. Problemas dessa ordem foram solucionados em laboratório, pela interpretação dos desenhos, das fotografias, das fichas e das cadernetas de campo.

Assim, a arqueologia de contrato pode e deve ser realizada levando em conta as observações mencionadas acima, procurando não apenas satisfazer as exigências das leis que regem a defesa e a proteção patrimonial, mas também contribuir com a construção do conhecimento científico sobre o passado, repassando-o para a população em geral e garantindo assim que as informações geradas concorram para a conservação do patrimônio arqueológico na Amazônia. 


\section{Referências}

AB'SABER, A. N. Brasil, paisagens de exceção: o litoral e o Pantanal mato-grossense, patrimônios básicos. Cotia, SP: Ateliê, 2006.

AITKEN, M. J. Physics and Archaeology. Nova York: Interscience, 1961.

ALVES, J. J. A.; LOURENÇO, J. S. Métodos geofísicos aplicados à arqueologia no estado do Pará. Boletim do Museu Paraense Emílio Goeldi, Série Geologia, v. 26, p. 1-52, 1981.

ALVES, M. A. M. S. et al. Morfodinâmica das praias de meso-macromarés da zona costeira do estado do Pará. In: X CONGRESSO DA ASSOCIAÇÃO BRASILEIRA DE ESTUDOS DO QUATERNÁRIO (ABEQUA), 10., 2005, Guarapari, ES. CD-ROM de resumos expandidos, n. 0258.pdf.

BARRETO, C. A construção de um passado pré-colonial: uma breve história da arqueologia no Brasil. Revista USP, São Paulo, n. 44, p. 32-51, dez. 1999/fev. 2000.

BUTZER, K. W. Arqueología - una ecología del hombre: método y teoría para un enfoque contextual. Barcelona: Bellaterra, 1989.

COSTA, F. H. J. A. Projeto baixo Tocantins: salvamento arqueológico na região de Tucuruí (Pará). Dissertação (Mestrado em Antropologia Social e Arqueologia) - Faculdade de Filosofia, Letras e Ciências Humanas, Universidade de São Paulo, São Paulo, 1993.

HODDER, I. New Generations of Spatial Analysis in Archeology. In: COLOQUIO SOBRE DISTRIBUCIÓNY RELACIONES ENTRE LOS ASENTAMIENTOS - ARQUEOLOGÍA ESPACIAL, 1984, Teruel, ES. p. 7-24.

LEHMANN, J. et al. Amazonian Dark Earths: Origin, Properties and Management. Dordrecht: Kluwer Academic, 2003.

LIGHTFOOT, K. G. Culture Contact Studies: Redefining the Relationship Between Prehistoric and Historical Archaeology. American Antiquity, Cambridge: Society for American Archaeology, v. 60, n. 2, p. 199-217, 1995.

LIMA, R. R.: TOURINHO, M. M.; COSTA, J. P. C. Várzeas flúvio-marinhas da Amazônia brasileira: características e possibilidades agropecuárias. Belém: Ficap, 2000.

LOPES, D. F;; SILVEIRA, M. I.; MAGALHÃES, M. Levantamento arqueológico. In: Projeto Estudo e Preservação de recursos Humanos e Naturais da Área do Projeto Ferro Carajás. Relatório final, vol. 1. Belém: Museu Paraense Emílio Goeldi, 1988.

LOPES, P. R. C. et al. Programa de Arqueologia Preventiva na Área do Projeto Bauxita Paragominas/PA. Relatório final. Belém: MPEG/Vale/Fidesa, 2008.

MARTÍNEZ, V. M. F; ZAPATERO, G. R. El análisis de territorios arqueológicos: una introducción crítica. In: COLOQUIO SOBRE DISTRIBUCIÓN Y RELACIONES ENTRE LOS ASENTAMIENTOS - ARQUEOLOGÍA ESPACIAL, 1984, Teruel, ES. p. 55-71. 
MUNSELL COLORS COMPANY. Munsell Soil Colors Charts. Baltimore, 1975.

NEVES, E. G. Duas interpretações para explicar a ocupação pré-histórica na Amazônia. In: TENÓRIO, M. C. (Org.). Pré-História da Terra Brasilis. Rio de Janeiro: Editora da UFRJ, 1999. p. 75-88.

OLIVEIRA, R. D. Zoneamento agro ambiental do município de Barcarena-Pará.

Dissertação (Mestrado) - Faculdade de Ciências Agrárias do Pará, Belém, 2002.

PEARSALL, D. M. Paleoethnobotany: A Handbook of Procedures. 2. ed. Cambridge: Academic Press, 2000.

PEREIRA, E. S. O potencial arqueológico na área da UHE-Santa Isabel. Belém: Museu Paraense Emilio Goeldi, 1999.

PEREIRA, E. M. B. Ecologia de paisagem aplicada à análise ambiental do sítio arqueológico Pa-Ba-84: Alunorte em Barcarena-PA. Dissertação (Mestrado em Geografia) - Instituto de Filosofia e Ciências Humanas, Universidade Federal do Pará, Belém, 2008.

RENFREW, C.; BAHN, P. Arqueología: teorías, métodos y práctica. Madri: Akal, 1993. (Serie Textos.)

ROOSEVELT, A. C. Arqueologia amazônica. In: CUNHA, M. C. (Org.). História dos índios no Brasil. São Paulo: Fapesp/SMC/Companhia das Letras, 2006. p. 53-86.

Moundbuilders of the Amazon: Geophysical Archaeology on Marajo Island, Brazil. San Diego: Academic Press, 1991.

ROSSETTI, D. F; GÓES, A. M. O neógeno da Amazônia oriental. Belém: MPEG, 2004. (Coleção Fredrich Katzer.)

SCHIFFER, M. Archaeological Context and Systemic Context. American Antiquity, v. 37, n. 2, p. 156-165, 1972.

SENNA, C. F. S. Condições paleoambientais relacionadas à ocupação da Baía de Guanabara, litoral de Cabo Frio e planície costeira do rio São João por sociedades pré-históricas: coletores-pescadores do litoral. Rio de Janeiro: Instituto de Geociências/UFRJ, 1991.

SENNA, C. S. F. et al. Paleoambientes e ocupação humana pré-histórica do estuário do rio Pará, Amazônia, no último milênio. In: CONGRESSO LATINO AMERICANO DE CIÊNCIAS DO MAR - COLACMAR, 12., 2007, Florianópolis,SC. CDROM de Resumos Expandidos.

SIMÕES, M. F. A pré-história da bacia Amazônica: uma tentativa de reconstrução. Aspectos da arqueologia amazônica. Instituto de Arqueologia Brasileira, Rio de Janeiro (catálogo), p. 5-21, 1983. 